\title{
Preparation and characterization of poly(ethylene oxide)/zinc oxide nanofibrous scaffold for chronic wound healing applications
}

\author{
Hamed Nosrati ${ }^{1, A-F}$, Mohammad Khodaei ${ }^{2, A-C, E, F}$, Mehdi Banitalebi-Dehkordi ${ }^{3, C, E, F}$, Morteza Alizadeh ${ }^{1, B, C, F}$, \\ Shiva Asadpour ${ }^{1,3, F}$, Esmaeel Sharifi ${ }^{4, A, F}$, Jafar Ai ${ }^{5, A, C, E, F}$, Mostafa Soleimannejad ${ }^{1,3, A-F}$ \\ ${ }^{1}$ Department of Tissue Engineering and Applied Cell Sciences, School of Advanced Technologies, Shahrekord University of Medical Sciences, Shahrekord, Iran \\ ${ }^{2}$ Department of Materials Science and Engineering, Golpayegan University of Technology, Golpayegan, Iran \\ ${ }^{3}$ Cellular and Molecular Research Center, Basic Health Sciences Institute, Shahrekord University of Medical Sciences, Shahrekord, Iran \\ ${ }^{4}$ Department of Tissue Engineering and Biomaterials, School of Advanced Medical Sciences and Technologies, Hamadan University of Medical Sciences, Hamadan, Iran \\ ${ }^{5}$ Department of Tissue Engineering and Applied Cell Sciences, School of Advanced Technologies in Medicine, Tehran University of Medical Sciences, Tehran, Iran \\ A - research concept and design; $\mathrm{B}$ - collection and/or assembly of data; $\mathrm{C}$ - data analysis and interpretation; \\ $D$ - writing the article; $E$ - critical revision of the article; $F$ - final approval of the article
}

Address for correspondence

Mostafa Soleimannejad

E-mail: soleimannejad@yahoo.com

Funding sources

This study was funded by Shahrekord University of Medical Sciences, Iran (Grant No. 3179).

Conflict of interest

None declared

Received on September 8, 2020

Reviewed on September 21, 2020

Accepted on 0ctober 12, 2020

Cite as

Nosrati H, Khodaei M, Banitalebi-Dehkordi M. Preparation and characterization of poly(ethylene oxide)/zinc oxide nanofibrous scaffold for chronic wound healing applications. Polim Med. 2020;50(1):41-51. doi:10.17219/pim/128378

DOI

10.17219/pim/128378

Copyright

๑) 2020 by Wroclaw Medical University

This is an article distributed under the terms of the

Creative Commons Attribution 3.0 Unported (CC BY 3.0)

(https://creativecommons.org/licenses/by/3.0/)

\begin{abstract}
Background. Skin, the first barrier to pathogens, loses its integrity and function after an injury. The presence of an antibacterial dressing at the wound site may prevent bacterial invasion and also improve the healing process.

Objectives. The current study aimed to fabricate a biomimetic membrane with antibacterial properties for healing chronic wounds.

Material and methods. The membranes, fabricated through electrospinning, are comprised of poly(ethylene oxide) (PEO) and zinc oxide nanoparticles (ZnO-NPs) as the main biomaterial and antibacterial agent, respectively. Antibacterial activity, cell attachment and viability were tested to evaluate the biological properties of the membranes. The optimal cell compatible concentration of ZnO-NPs was determined for further studies. In vitro characterization of the membranes was performed to confirm their suitable properties for wound healing.

Results. The antibacterial PE0/ZnO-NP membrane containing $2 \%$ of nanoparticles showed no cell toxicity, and human fibroblast cells were able to adhere and proliferate on the scaffold. The in vitro results from the tensile test, wettability, porosity, and protein adsorption revealed appropriate properties of the membrane as a scaffold for skin tissue engineering.

Conclusions. Synthetic polymers have been widely used for tissue engineering applications. The proper characteristics of PEO nanofibers, including a high ratio of surface/volume, moderate hydrophilicity and good mechanical properties, make this polymer interesting for skin regeneration. The results demonstrate the potential of the antibacterial PEO/ZnO-NP membrane to be used as an engineered scaffold to improve the wound healing process.
\end{abstract}

Key words: zinc oxide, wound healing, antibacterial, electrospun membrane, poly(ethylene oxide) 


\section{Introduction}

Skin, the largest and heaviest organ of mammals, provides a functional barrier to protect the human body from its surroundings. It protects the underlying tissues against microbial pathogens. As the primary barrier, it is exposed to harmful situations, such as chemical, mechanical and thermal influences, as well as microbial invasions. ${ }^{1}$ Engineered scaffolds can encourage regeneration in cases of excessive skin loss due to severe dermal wounds. Significant effort has been made over the last decades to produce biomimetic substitutes. ${ }^{2}$ Tissue engineering approaches are promising tools for creating scaffolds that could mimic the microstructure of the native tissue in order to regenerate it. In the field of skin tissue engineering, an ideal biomimetic scaffold/substitute should protect the injured area from infection and prevent fluid loss. The appropriate mechanical properties of these scaffold/ substitute could also improve the wound healing process. ${ }^{3}$

Different synthetic and natural polymers are used to fabricate protective scaffolds for wound healing. (Hydro-) gels, membranes, films, as well as micro- and nanofibers are the most common scaffolds in skin tissue engineering. ${ }^{4}$ Among skin substitutes, nanofibers have captured great attention for use as wound dressings and scaffolds. Nanofibers provide a topography similar to the native extracellular matrix (ECM) that encourages cell attachment, migration and differentiation. ${ }^{5}$ High porosity, large surface area/volume ratio and suitable mechanical properties make nanofibers interesting for biomedical applications. Nanofibers can be fabricated with different methods and techniques such as self-assembly, drawing, phase separation, and electrospinning. The high surface area of electrospun fibers facilitates cell adhesion as well as gas exchange. ${ }^{6}$

Through the selection of biomaterial and optimization of electrospinning process, parameters such as flow rate, polymer solution concentration, solvent, distance, and voltage, a wide range of scaffolds that vary in morphology, fiber size and porosity can be obtained. ${ }^{7}$ Most of the biomaterials used for skin tissue engineering have been natural-based biopolymers. Although these polymers induce cell adhesion well, they usually have poor mechanical properties; the electrospinning of these polymers is also challenging. To overcome such drawbacks, synthetic polymers such as poly(ethylene oxide) (PEO), polyvinyl alcohol (PVA) and poly(lactide-co-glycolide) (PLGA) have been blended with natural biopolymers to enable the production of nanofibrous scaffolds. ${ }^{8,9}$

Poly(ethylene oxide) is a synthetic polymer usually used as a second component to facilitate the electrospinning of other polymers such as silk fibroin, chitosan and collagen. Using this spinnable synthetic polymer singly could provide high mechanical properties and enhance cell adhesion. It can also limit the use of organic solvents to improve the biocompatibility of the fibers. ${ }^{10}$
Zinc oxide is a biologically safe material that has captured much attention due to its antibacterial properties. The nanosized forms of this material have a larger surface area, resulting in a greater impact. The presence of $\mathrm{ZnO}$ NPs in nanofibers reportedly improves the antibacterial activity of fibrous membranes. ${ }^{11,12}$

In the present study, an antibacterial electrospun scaffold composed of PEO fibers and ZnO-NPs was prepared. In vitro characterization of the electrospun scaffold was performed to evaluate the biocompatibility and potential of the nanofibrous membrane to be used as an engineered scaffold for wound healing and skin tissue engineering applications. This is the first report of the preparation and in vitro characterization of $\mathrm{PEO} / \mathrm{ZnO}-\mathrm{NP}$ electrospun membranes for skin tissue engineering applications.

\section{Material and methods}

\section{Solution preparation}

Poly(ethylene oxide) solutions were prepared by dissolving PEO (Sigma-Aldrich, St. Louis, USA; CAS No. 25322-68-3) (average molecular weight: 900,000) in $80 \%$ acetic acid (Sigma-Aldrich; CAS No. 64-19-7) at a concentration of $4 \% \mathrm{w} / \mathrm{v}$. ZnO-NPs were purchased from US Research Nanomaterials (Houston, USA; Stock \#US3590). Prior to loading, the size distribution and morphology of the ZnO-NPs were determined using dynamic light scattering (DLS) (Horiba Scientific SZ-100 Nanoparticle Analyzer; Horiba, Kyoto, Japan) and scanning electron microscopy (SEM) (S3400 Scanning Electron Microscope; Hitachi, Tokyo, Japan). After characterization of the nanoparticles, different concentrations of $\mathrm{ZnO}-\mathrm{NPs}(0.5 \%, 1 \%, 2 \%, 3 \%$, and $4 \% \mathrm{w} / \mathrm{w})$ were added to the PEO solution while stirring.

\section{Electrospinning process}

Each sample was sonicated for $5 \mathrm{~min}$ and loaded in a 5 - $\mathrm{mL}$ plastic syringe with an 18-gauge stainless steel needle. Fibers were collected on a rotating drum collector at a speed of $700 \mathrm{rpm}$. The PEO-ZnO solutions were electrospun on an electrospinning device (Model ANSTCON/VI; Asian NanoStructure Technology Company, Tehran, Iran) at a voltage of $22 \mathrm{kV}$, flow rate of $0.8 \mathrm{~mL} / \mathrm{h}$ and needle-to-collector distance of $180 \mathrm{~mm}$. The PEO solution was electrospun to produce PEO fiber as a control group.

\section{Cross-linking of membranes}

The electrospun membranes were dried for $48 \mathrm{~h}$ at room temperature and then cross-linked by exposure to glutaraldehyde (Grade I, 25\% in $\mathrm{H}_{2} \mathrm{O}$; Sigma-Aldrich; CAS No. 11130-8) vapor for $12 \mathrm{~h}$. The cross-linked mats were heated at $80^{\circ} \mathrm{C}$ for $4 \mathrm{~h}$ to remove residual amounts of glutaraldehyde. 


\section{Biological properties of the electrospun membranes}

\section{Evaluation of antibacterial activity}

The antibacterial activity of ZnO-NP-containing PEO scaffolds were studied against gram-negative (Escherichia coli) and gram-positive (Staphylococcus aureus) bacteria using the disc diffusion method. ${ }^{13}$ A Mueller-Hinton (MH) agar plate was prepared by dissolving $38 \mathrm{~g}$ of $\mathrm{MH}$ (ibresco, Tehran, Iran; CAT No. i23118) powder in $1 \mathrm{~L}$ of distilled water heated with frequent agitation and boiled to completely dissolve the powder. The prepared liquid medium was sterilized at $120^{\circ} \mathrm{C}$ for $1 \mathrm{~h}$ in the autoclave. The medium was allowed to cool to room temperature and poured into sterilized 9-cm Petri dishes. After cooling overnight, the bacteria were swabbed across the culture dishes. The scaffolds were punched into discs with a diameter of $6 \mathrm{~mm}$. The punched discs were placed on the surface of the culture medium. The Petri dishes were incubated at $37^{\circ} \mathrm{C}$ for $24 \mathrm{~h}$. The effectiveness of the antibacterial components was determined by measuring the inhibition zone, i.e., the area around the disc where no colonies were formed. The diameters of the inhibition zones were measured using ImageJ Software v. $1.52 \mathrm{v}$ (National Institutes of Health, Bethesda, USA) and presented in millimeters.

\section{Evaluation of cell viability}

Adult human dermal fibroblasts were seeded on electrospun membranes with different concentrations of the $\mathrm{ZnO}-\mathrm{NPs}(0 \%, 0.5 \%, 1 \%, 2 \%, 3 \%$, and $4 \%)$. After sterilization with ethanol $70 \%, 5 \times 10^{3}$ cells were seeded on each sample in 96 -well plates and incubated at $37^{\circ} \mathrm{C}$ with $94 \%$ humidity and $5 \% \mathrm{CO}_{2}$. Cell viability and proliferation were monitored at days 1, 3 and 7 using MTT assay. Dulbecco's modified Eagle's medium (DMEM) (Gibco, Waltham, USA; Mfr. No. Gibco ${ }^{\text {TM }}$ 31600083) enriched with 10\% of fetal bovine serum (FBS) (Gibco, Mfr. No. Gibco ${ }^{\text {TM }}$ 10082139) and 1\% penicillin/streptomycin (Gibco, Mfr. No. Gibco $^{\mathrm{TM}}$ 15140122) was used as culture medium. At each time point, $20 \mu \mathrm{L}$ of MTT solution (Sigma-Aldrich; CAS No. 298-93-1) was added to each well. Cell culture plates were incubated for $3 \mathrm{~h}$; then, the media was replaced with $200 \mu \mathrm{L}$ of dimethyl sulfoxide (DMSO) (Sigma-Aldrich; CAS No.67-68-5), and the cultures were incubated for another $30 \mathrm{~min} .{ }^{14,15}$ Finally, the absorbance of each sample was determined using a BioTek $800^{\mathrm{TM}}$ TS Absorbance Reader (BioTek Instruments Inc., Winooski, USA) at $570 \mathrm{~nm}$. Each sample was evaluated in triplicate.

\section{Cell attachment and morphology}

Following the determination of the optimal cell-compatible concentration of $\mathrm{ZnO}-\mathrm{NPs}$, adherence of human fibroblast cells to the membrane was observed using SEM.
Scaffolds were placed into 48 -well plates, and $50 \times 10^{4}$ cells were seeded onto the membranes and cultured for 2 days. Membranes were washed 3 times with phosphatebuffered saline (PBS) (Merck Millipore, Burlington, USA; Millipore Sigma ${ }^{\text {TM }}$ 65074L). Then, paraformaldehyde 4\% (Thermo Fisher Scientific, Waltham, USA; MDL No. MFCD00133991) was added for $90 \mathrm{~min}$. The samples were dehydrated in ascending concentrations of ethanol (60\%, 70\%, 80\%, 90\%, and 96\%) for $10 \mathrm{~min}$ in each. Samples were sputtered with gold and studied using SEM.

\section{Characterization of the electrospun membranes}

\section{SEM, FESEM and EDS analyses of the electrospun fibers}

The morphology and size of PEO nanofibers were determined with the obtained SEM images. The average diameters of the fibers were determined by measuring random fibers selected from different fields. Field emission scanning electron microscopy (FESEM) and energy-dispersive $\mathrm{X}$-ray spectroscopy (EDS) were performed to investigate the incorporation and dispersion of the $\mathrm{ZnO}$-NPs.

\section{ATR-FTIR analysis}

To characterize the final composition of the nanofibrous scaffolds, attenuated total reflectance-Fourier transform infrared spectroscopy (ATR-FTIR) analyses were performed. The spectra were obtained using a Thermo Fisher Scientific iS10 FTIR spectrophotometer. The resolution and spectral range were $4 \mathrm{~cm}^{-1}$ and $4000-400 \mathrm{~cm}^{-1}$, respectively.

\section{Mechanical properties}

The mechanical properties of the membranes were evaluated with tensile tests using a SANTAM testing machine (STM-5 Model; SANTAM Co. Ltd., Tehran, Iran). The tested membranes were $80 \times 20 \mathrm{~mm}$ in size and had thicknesses of $0.45-0.59 \mathrm{~mm}$. The testing speed was $1 \mathrm{~mm} / \mathrm{min}$ for all samples. Stress-strain curves of the samples obtained from force-extension curves. The average for 5 samples $(n=5)$ was measured to determine the mechanical properties of each membrane.

\section{Determination of porosity of the scaffolds}

The porosity of the electrospun membranes was determined using a method described elsewhere. ${ }^{16}$ In this method, dry weights of the scaffolds were recorded, and then the scaffolds were immersed in absolute ethanol for $1 \mathrm{~h}$. Wet weights were also recorded. Three specimens were evaluated for each sample and the averages were reported. The porosity of each sample was determined through the following equation: 


$$
\mathrm{p}(\%)=\frac{\mathrm{W}_{\mathrm{s}}-\mathrm{W}_{\mathrm{d}}}{\mathrm{D}_{\text {ethanol }}-\mathrm{V}_{\text {scaffold }}} \times 100
$$

where $\left(\mathrm{P}\right.$ - porosity, $\mathrm{W}_{\mathrm{s}}$ - swollen scaffold weight, $\mathrm{W}_{\mathrm{d}}-\mathrm{dry}$ scaffold weight, $\mathrm{D}_{\text {ethanol }}$ - ethanol density, $\mathrm{V}_{\text {scaffold }}$ - volume of the swollen scaffold).

\section{Wettability of membrane surface}

The wettability of the scaffolds was determined by measuring the contact angle at the surface of the electrospun membranes. The water contact angles of $3(n=3)$ samples were measured using ImageJ software and the average was reported as the contact angle of each membrane.

\section{Protein adsorption}

Protein adsorption on membrane surfaces was assessed with a procedure described by Miguel et al. ${ }^{8}$ The scaffolds were placed in a 48-well plate. Then, $300 \mu \mathrm{L}$ of bovine serum albumin (BSA) (Sigma-Aldrich; CAS No. 904846-8) was added to the surface of the scaffolds, and they were incubated at $37^{\circ} \mathrm{C}$ for $0.5 \mathrm{~h}, 1 \mathrm{~h}, 2 \mathrm{~h}, 6 \mathrm{~h}$, and $12 \mathrm{~h}$. Phosphate-buffered saline was used to wash the non-adherent BSA, and then $300 \mu \mathrm{L}$ of $2 \%$ sodium dodecyl sulfate (SDS) (Sigma-Aldrich; CAS No. 151-21-3) was added to each sample. After overnight incubation, a bicinchoninic acid (BCA) kit (DNAbiotech Co., Tehran, Iran; Cat No.: DB9684-50 mL) was used to investigate the protein absorption of the membranes.

\section{Statistical analysis}

One-way analysis of variance (ANOVA) with the Newman-Keuls post hoc test was performed to evaluate the results. Statistical comparisons between 2 groups were carried out using the $\mathrm{t}$-test. A p-value lower than 0.05 was considered a significant change.

\section{Results}

\section{Nanoparticles characterization}

The results from DLS and SEM analyses revealed the size distribution, average size and morphology of the $\mathrm{ZnO}$ NPs. As seen in Fig. 1, the average size of the ZnO-NPs was $74 \mathrm{~nm}$ and the size distribution was from $60 \mathrm{~nm}$ to $90 \mathrm{~nm}$. The SEM image confirmed the nanosize of the particles. Nanoparticles in this range of size can easily be incorporated into electrospun fibers as other studies have reported. ${ }^{17}$

\section{SEM, FESEM, and EDS analyses of electrospun fibers}

The diameter of the fibers was determined with SEM analysis, as shown in Fig. 2. The images show randomly oriented electrospun PEO fibers with an average diameter of $362.5 \mathrm{~nm}$. The PEO/ZnO-NPs fibers exhibit a similar morphology with a mean diameter of $315.3 \mathrm{~nm}$

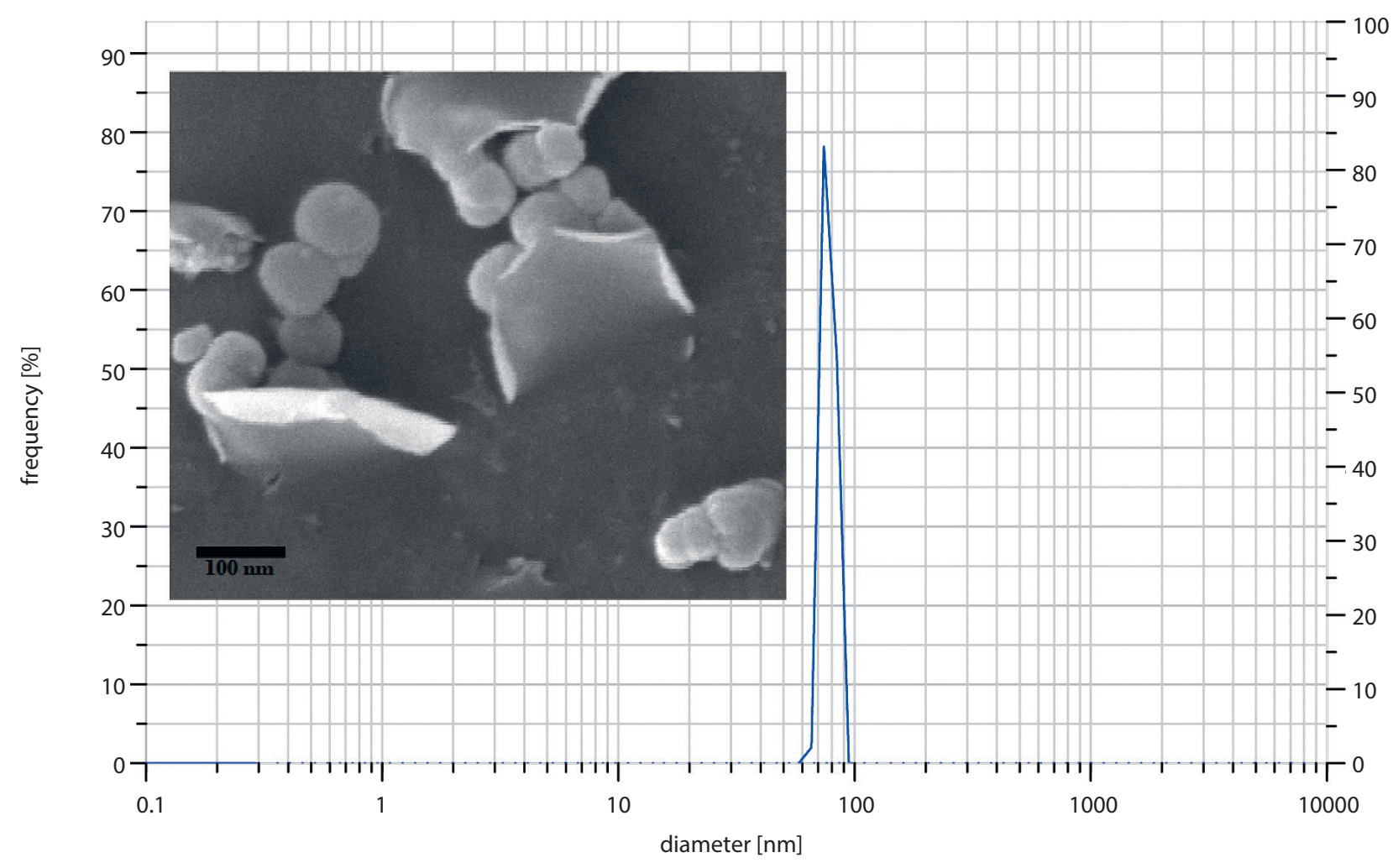

Fig. 1. SEM image and particle size distribution of zinc oxide nanoparticles measured using dynamic light scattering (DLS) method 

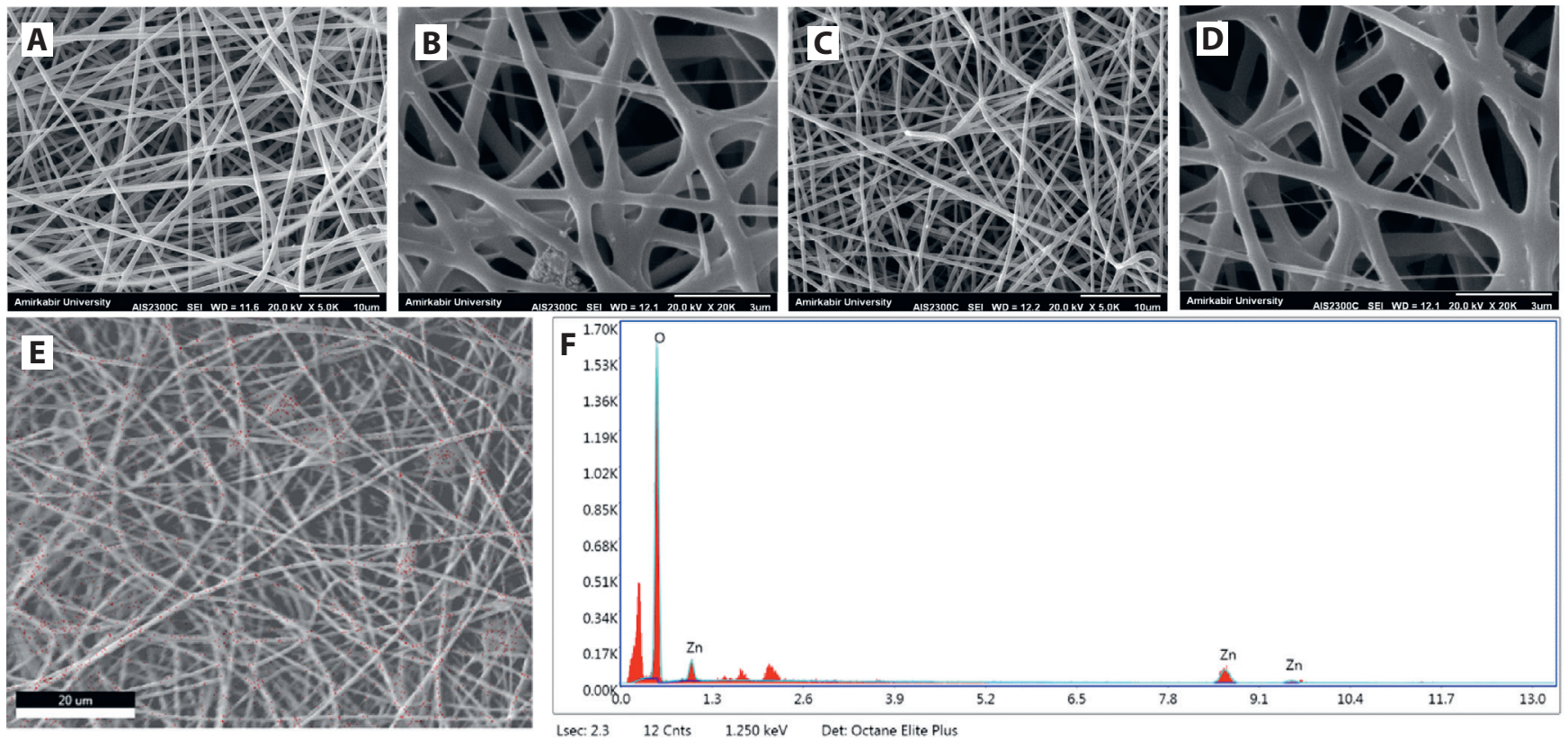

Fig. 2. SEM, FESEM and EDS analyses of the electrospun fibers. A. PEO fibers; B. Cross-linked PEO fibers; C. PEO/ZnO-NPs fibers; D. Cross-linked PEO/ZnO-NPs fibers; E. FESEM analysis of PEO/ZnO-NPs fibers; F. EDS analysis of PEO/ZnO-NPs fibers
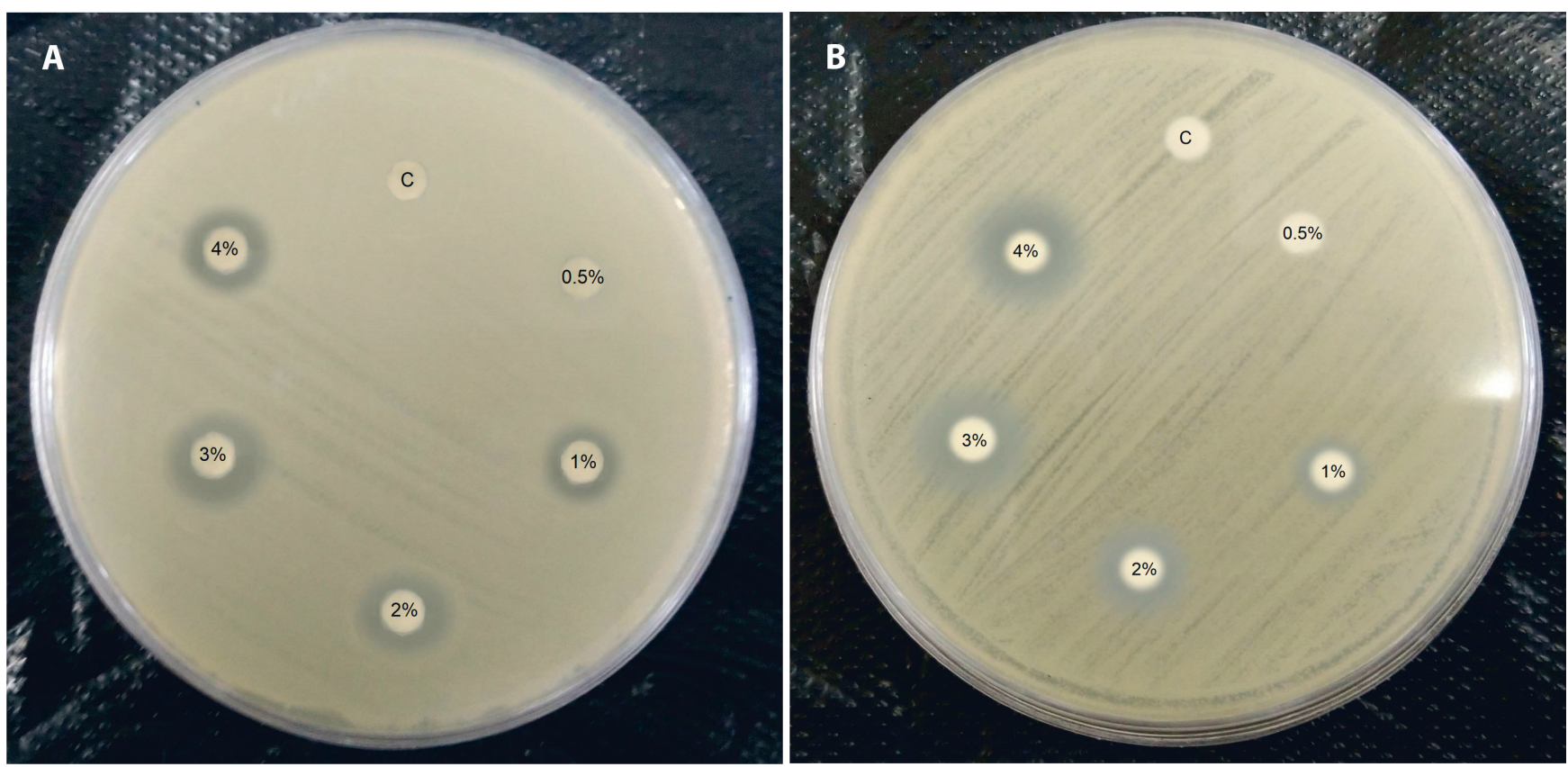

Fig. 3. Antibacterial activity of ZnO-NPs loaded into PEO fibers with different concentrations (0-4\% w/w) against (A) E. coli and (B) S. aureus

(Fig. 2A,C). The images also confirmed the suitability of the crosslinking procedure (Fig. 2B,D). The FESEM image of $\mathrm{ZnO}$-NP-loaded nanofibers demonstrated the proper $\mathrm{ZnO}-\mathrm{NP}$ dispersion inside the PEO fibers (Fig. 2E). The EDS analysis of PEO/ZnO-NP fibers confirmed the presence of zinc and oxygen in the structure of the incorporated scaffold (Fig. 2F).

\section{Biological properties of the electrospun membranes}

Evaluation of antibacterial activity

Antibacterial properties were characterized with the disc diffusion method using gram-negative (E. coli) and gram-positive (S. aureus) bacteria. ${ }^{18}$ The inhibition zones (Fig. 3) were measured and presented in Table 1. 
Table 1. Effects of the incorporated ZnO-NPs on the antibacterial properties of the scaffolds

\begin{tabular}{|l|c|c|c|c|c|c|}
\multicolumn{1}{c|}{ Scaffold type } & $\begin{array}{c}\text { PEO } \\
\text { (control) }\end{array}$ & $\begin{array}{c}\text { PEO/ZnO-NPs } \\
(0.5 \% \text { ZnO-NPs })\end{array}$ & $\begin{array}{c}\text { PEO/ZnO-NPs } \\
(1 \% \text { ZnO-NPs) }\end{array}$ & $\begin{array}{c}\text { PEO/ZnO-NPs } \\
(2 \% \text { ZnO-NPs) }\end{array}$ & $\begin{array}{c}\text { PEO/ZnO-NPs } \\
(3 \% \text { ZnO-NPs) }\end{array}$ & $\begin{array}{c}\text { PEO/ZnO-NPs } \\
(4 \% \text { ZnO-NPs) }\end{array}$ \\
\hline Inhibition zone for E. coli $[\mathrm{mm}]$ & 0 & 0.2 & 2.16 & 3.67 & 4.06 & 4.09 \\
Inhibition zone for S. aureus [mm] & 0 & 0 & 1.95 & 3.21 & 3.98 & 4.46 \\
\hline
\end{tabular}

\section{Evaluation of cell viability}

The viability of human fibroblast cells was evaluated on day 1, 3 and 7 after cell seeding in the presence of scaffolds through the MTT assay (Fig. 4). Membranes containing $0.5 \%, 1 \%, 2 \%$, and $3 \%$ of $\mathrm{ZnO}-\mathrm{NP}$ showed no significant cytotoxicity effect $(p>0.05)$. Cell viability decreased significantly over 7 days for the $4 \%$ group compared to the control $(\mathrm{p}<0.01)$. Scaffolds containing $2 \%$ of $\mathrm{ZnO}-\mathrm{NPs}$ showed the best compatibility compared to other groups. Therefore, $\mathrm{PEO} / \mathrm{ZnO}-\mathrm{NPs}$ containing $2 \%$ of nanoparticles were selected for further studies.

\section{Cell attachment and morphology}

The adhesion and morphology of human fibroblast cells were analyzed with SEM. Figure 5 shows the attachment of cells onto the PEO and PEO/ZnO-NP (containing 2\% of nanoparticles) membranes.

\section{Characterization of the electrospun membranes}

\section{ATR-FTIR analysis}

The ATR-FTIR spectra of PEO and PEO/ZnO-NPs electrospun membranes are presented in Fig. 6. The spec-

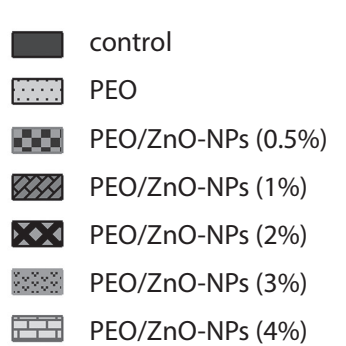

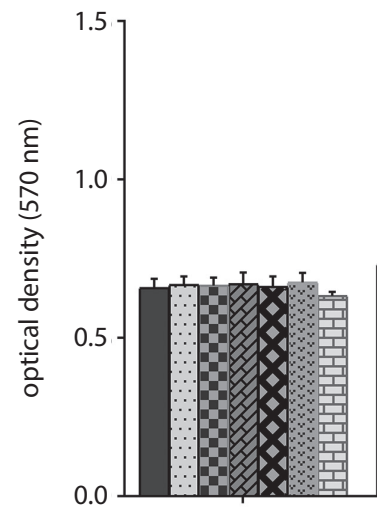

24

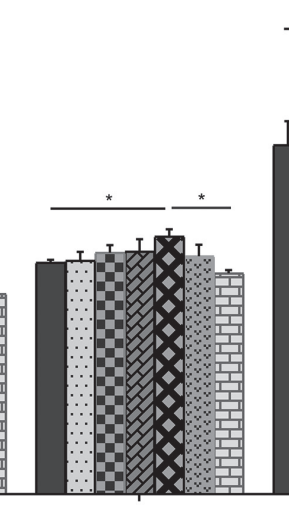

72

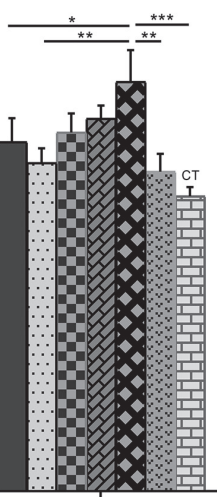

168 culture time $[\mathrm{h}]$

Fig. 4. In vitro cytotoxicity and cell viability of the scaffolds. MTT assay results for adult skin fibroblast proliferation on PEO and PEO/ZnO-NPs fibers and control. Data is shown as mean $\pm S D(n=3)$

${ }^{*} \mathrm{p}<0.05 ;{ }^{* *} \mathrm{p}<0.01 ;{ }^{* * *} \mathrm{p}<0.001 ; \mathrm{CT}-$ cell toxicity.
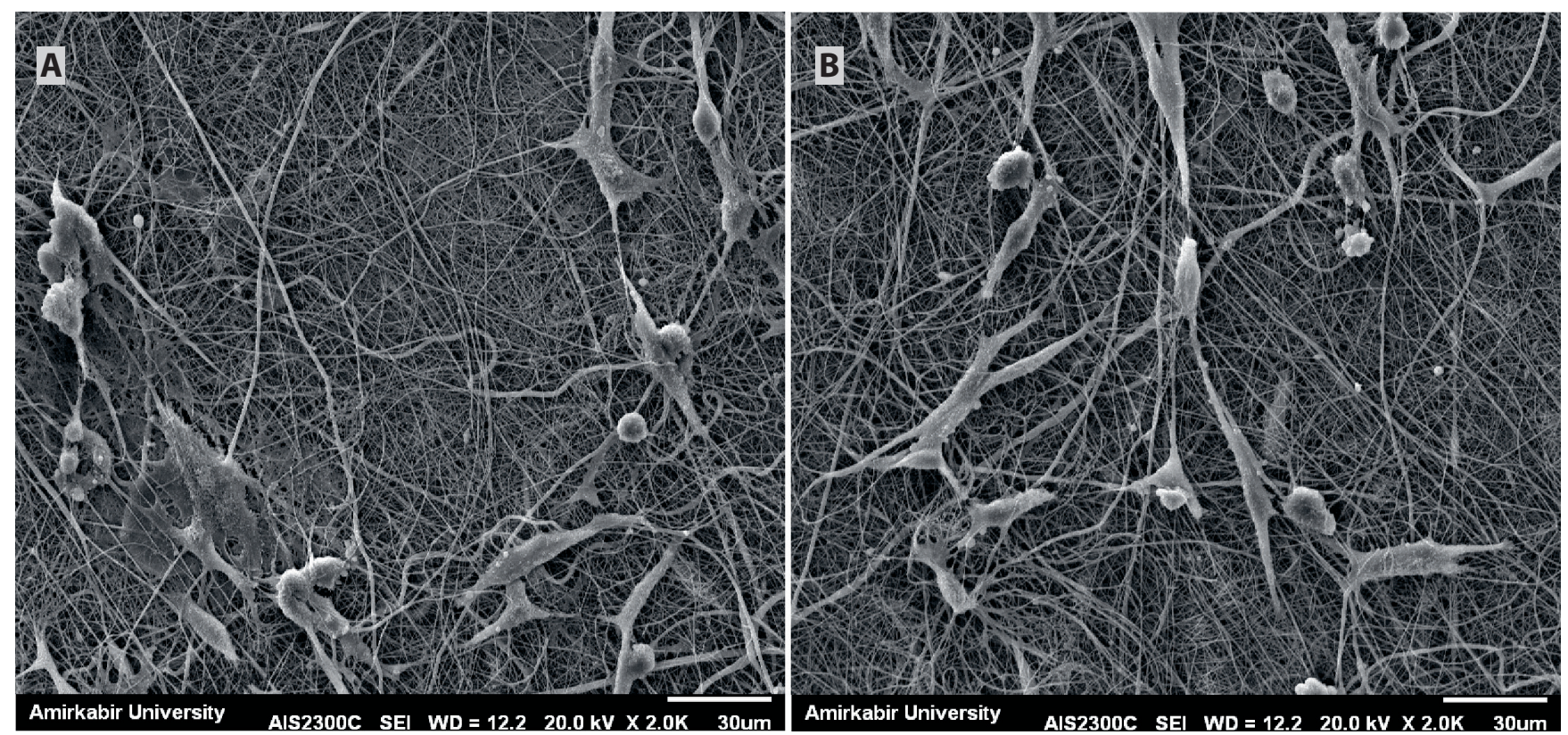

Fig. 5. SEM micrographs of cell attachment onto (A) PEO fibers and (B) PEO/ZnO-NPs (2\%) scaffolds 


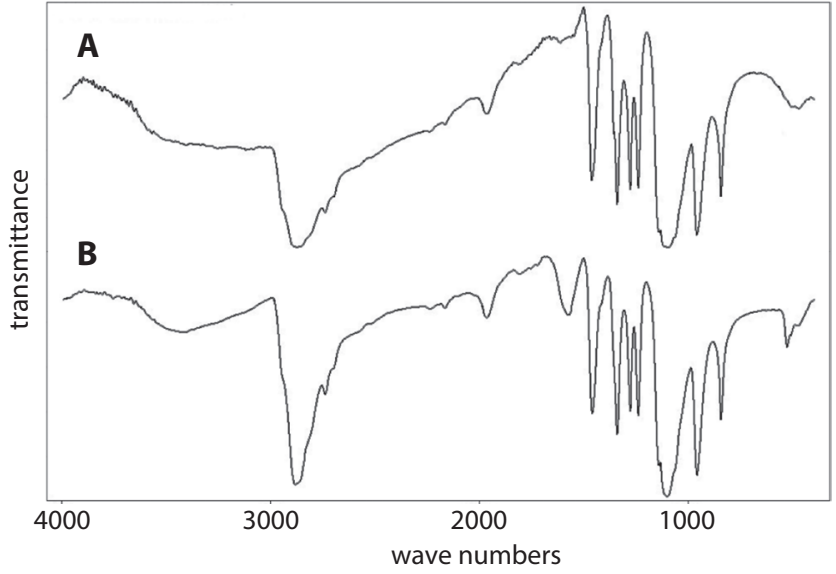

Fig. 6. ATR-FTIR spectra of (A) PEO and (B) PEO/ZnO-NPs (2\%) fibers

trum of the pure PEO (Fig. 6A) shows characteristic peaks in the regions of $1462 \mathrm{~cm}^{-1}, 1342 \mathrm{~cm}^{-1}, 1280 \mathrm{~cm}^{-1}$, and $844 \mathrm{~cm}^{-1}$ that represent different bonds of $\mathrm{CH}_{2}$ in scissoring, wagging, twisting, and rocking forms. The sharp peak at $2881 \mathrm{~cm}^{-1}$ is related to $\mathrm{CH}$ stretching, and the smooth peak at $3464 \mathrm{~cm}^{-1}$ shows the presence of the $\mathrm{OH}$ group. Other peaks at $1141 \mathrm{~cm}^{-1}, 1095 \mathrm{~cm}^{-1}$ and $956 \mathrm{~cm}^{-1}$ are related to $\mathrm{C}-\mathrm{O}-\mathrm{C}$ stretching, which are responsible for the semi-crystalline phase of PEO. ${ }^{19}$ The spectrum of the PEO/ZnO-NPs (Fig. 6B) displays the characteristic peaks of $\mathrm{ZnO}-\mathrm{NPs}$ at $3410 \mathrm{~cm}^{-1}(\mathrm{OH}$ groups on the surface), $1577 \mathrm{~cm}^{-1}$ (Zn hydroxo-acetate complex) and $528 \mathrm{~cm}^{-1}$ ( $\mathrm{Zn}-\mathrm{O}$ bond). ${ }^{20}$

\section{Mechanical properties}

The PEO membranes showed a Young Modulus of $13.72 \pm 3.11 \mathrm{MPa}$, whereas cross-linked ones showed a value of $24.98 \pm 4.26 \mathrm{MPa}$, which indicated a statistically significant difference after crosslinking $(p<0.05)$. Similar changes were observed for PEO/ZnO-NPs scaffolds, which were $15.67 \pm 2.96 \mathrm{MPa}$ before crosslinking and $28.15 \pm 4.49 \mathrm{MPa}$ for the cross-linked scaffolds $(\mathrm{p}<0.05)$ (Fig. 7).

\section{Determination of scaffolds porosity}

Porosities of the $\mathrm{PEO}$ and $\mathrm{PEO} / \mathrm{ZnO}$-NPs scaffolds were determined using the ethanol displacement method. ${ }^{21}$ As seen in Fig. 8, the PEO membranes revealed a porosity of $83.10 \pm 3.50 \%$. Incorporation of $\mathrm{ZnO}-\mathrm{NPs}$ slightly increased the porosity of the membrane to $86.78 \pm 7.42 \%$. This increase was not statistically significant $(\mathrm{p}>0.05)$.

\section{Wettability of membrane surface}

The electrospun PEO and PEO/ZnONP membranes showed water contact angle values of $41.06 \pm 3.26^{\circ}$ and $35.41 \pm 3.44^{\circ}$, respectively (Fig. 9).

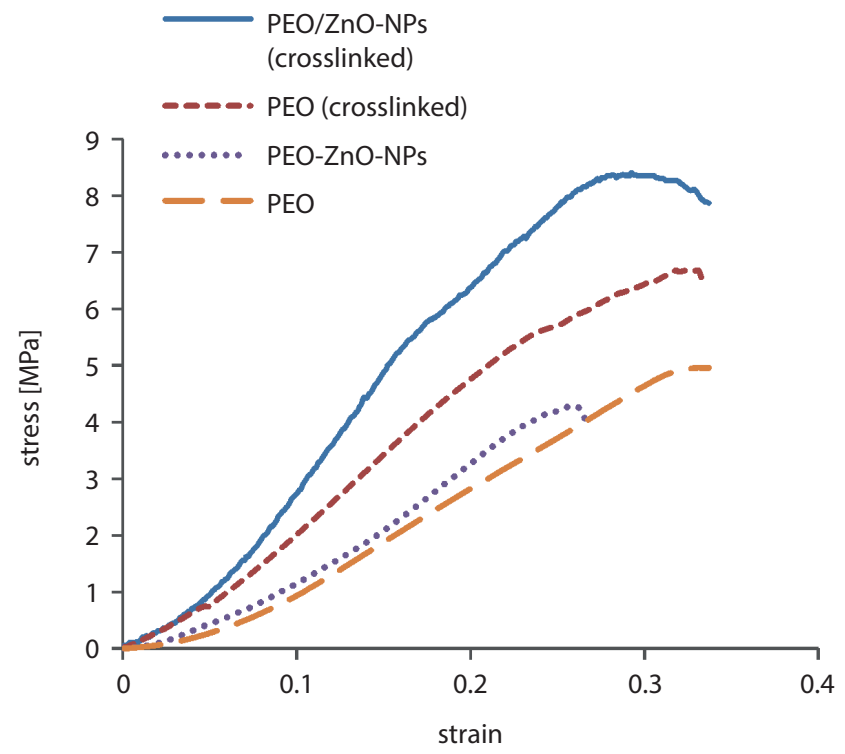

Fig. 7. Mechanical properties of electrospun PEO and PEO/ZnO-NPs (2\%) fibers before and after cross-linking

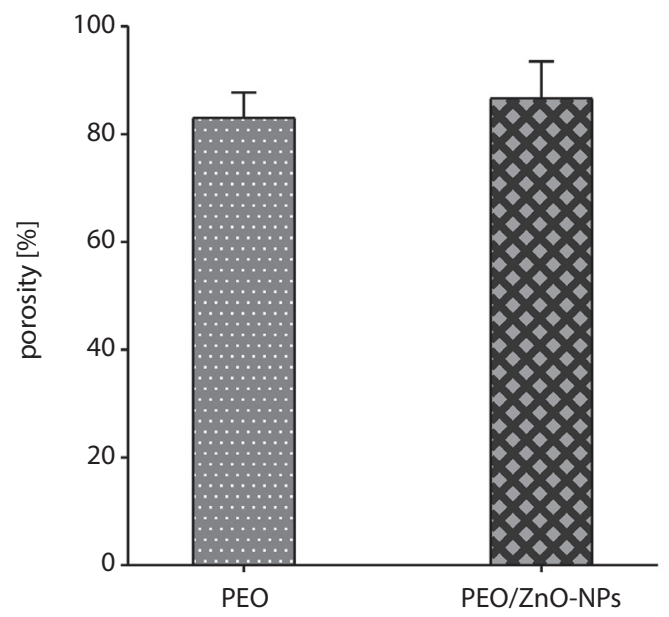

Fig. 8. The porosity of electrospun fibers: (A) PEO and (B) PEO/ZnO-NPs (2\%)

\section{Protein adsorption}

The BCA assessment kit for protein adsorption revealed a time-dependent increase in adsorbed albumin after $0.5 \mathrm{~h}, 1 \mathrm{~h}, 2 \mathrm{~h}, 6 \mathrm{~h}$, and $24 \mathrm{~h}$ of incubation for both membranes. No statistically significant changes were detected at different times between the 2 groups ( $p>0.05$ ). The results are presented in Fig. 10.

\section{Discussion}

When engineered scaffolds are used as skin substitutes or wound dressings, they are meant to protect the injured site from infection, moisture loss and physical damage. They are also supposed to support the wound mechanically. Cell attachment, as a key issue in the healing process, is affected by the porosity and surface hy- 


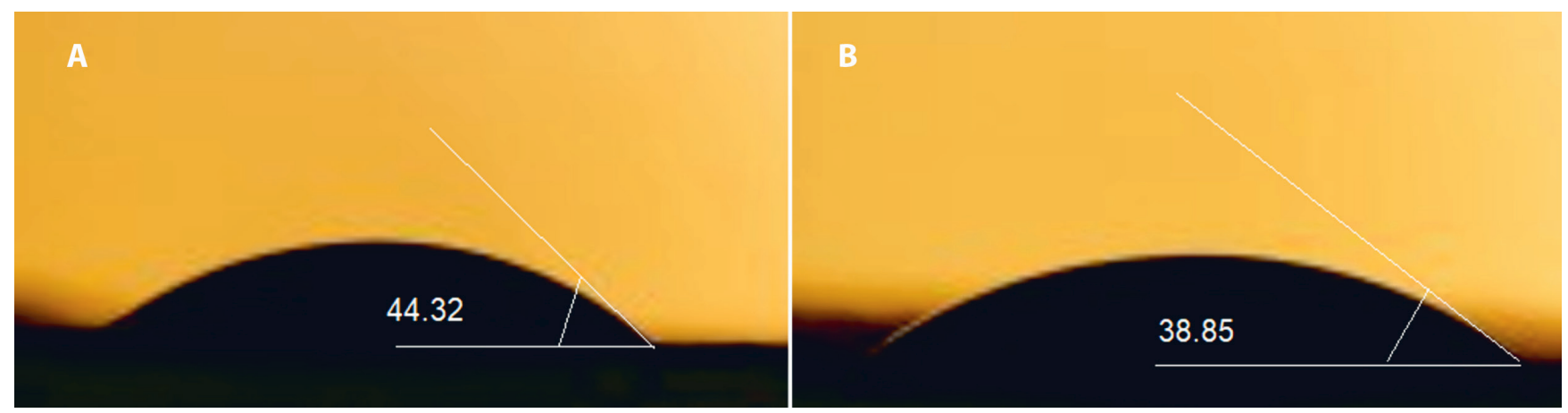

Fig. 9. Contact angles of deionized water droplet on (A) PEO and (B) PEO/ZnO-NP (2\%) membranes

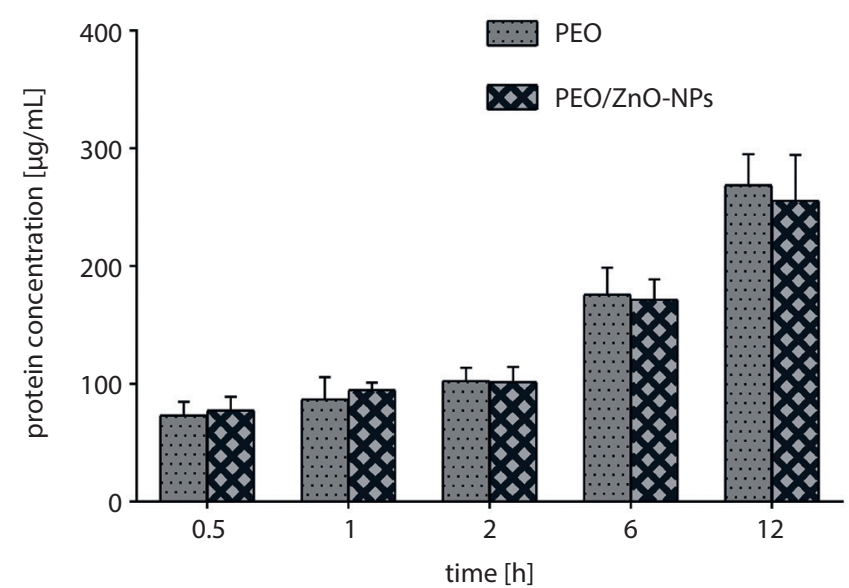

Fig. 10. Protein adsorption on the membrane surface. Amount of albumin absorbed on the surface of scaffolds after $0.5 \mathrm{~h}, 1 \mathrm{~h}, 2 \mathrm{~h}, 6 \mathrm{~h}$, and $12 \mathrm{~h}$

drophilicity of the substrate. ${ }^{22}$ A wide range of materials and various techniques are used to produce such scaffolds. In the present study, antibacterial electrospun scaffolds were fabricated using PEO as the main supportive biomaterial and $\mathrm{ZnO}-\mathrm{NPs}$ as the antibacterial agent. Poly(ethylene) glycol confers to the membrane good mechanical properties, preserves wound moisture and mimics native ECM topography. ${ }^{23,24}$ The porous structure of the PEO and PEO/ZnO-NP scaffolds was designed to be able to promote the exchange of gas and nutrients, and to support cell proliferation and migration. Biological assessments and in vitro characterization of membranes were performed to evaluate their suitability for skin tissue engineering.

The results of the SEM analysis and the DLS demonstrate the nanosize of the particles that make them ideal for incorporation into electrospun fibers (Fig. 1). Thinner fibers were fabricated by incorporating $\mathrm{ZnO}-\mathrm{NPs}$ due to a slight decrease in the viscosity of the solution (Fig. 2A,C). Scanning electron microscopy images of the cross-linked scaffolds (Fig. 2B,D) confirm the suitable method of crosslinking for PEO and PEO/ZnO-NP nanofibers. Other studies had previously reported a similar effect on the diameter of synthetic polymer fibers when nanoparticles or other agents were added to the so- lution. ${ }^{8}$ Furthermore, the nanofibers produced in the current study have an average diameter comparable to that of the collagen fibers present in native ECM $(60-400 \mathrm{~nm})$. Son et al. developed ultrafine nanofibrous membranes by electrospinning PEO dissolved in different types of solvents. ${ }^{25}$ The average diameters were close to those in the current study.

Skin is the first barrier against microorganisms. Microorganism invasion could occur during wound healing and interfere with the healing process. Therefore, antibacterial activity is a significant advantage for a wound dressing or skin scaffold. ${ }^{26,27}$ The PEO membrane had no bactericidal impact. The inhibition zone for E. coli and S. aureus increased slightly with increasing $\mathrm{ZnO}-\mathrm{NPs}$ (Fig. 3). Therefore, the antibacterial activity of the PEO/ZnO-NPs could be attributed to the nanoparticles of $\mathrm{ZnO}$. Other investigations have demonstrated the bactericidal properties of these nanoparticles when they are incorporated into other natural or synthetic polymers. ${ }^{11,28,29}$ The greatest inhibition zone belongs to the $\mathrm{PEO} / \mathrm{ZnO}-\mathrm{NP}$ membrane with $4 \% \mathrm{w} / \mathrm{w}$ of nanoparticles. The MTT assay results, however, showed cell toxicity effects. The optimum cell-compatible concentration of ZnO-NPs with no toxicity was $2 \% \mathrm{w} / \mathrm{w}$ with inhibition zones of $3.67 \mathrm{~mm}$ and $3.21 \mathrm{~mm}$ for $E$. coli and $S$. aureus, respectively (Table 1). Other studies have shown the dose-dependent cytotoxicity of $\mathrm{ZnO}-\mathrm{NPs}$ for human epidermal keratinocytes and lung epithelial cells. ${ }^{30}$ Some other studies have shown the cytotoxicity of these nanoparticles in different cell types. ${ }^{31,32}$ As a result, the PEO membrane comprised of $2 \% \mathrm{w} / \mathrm{w} \mathrm{ZnO}-\mathrm{NPs}$ was chosen for further studies.

Interaction between cells and ECM components is critical for stabilizing the three-dimensional structure and retrieving tissue function during tissue remodeling in the wound healing process. ${ }^{33,34}$ A skin scaffold should improve cell adhesion, proliferation and migration to enhance the wound healing process. Scanning electron microscopy images revealed the adhesion of human fibroblast cells to the PEO/ZnO-NP membrane containing 2\% nanoparticles (Fig. 5). Fibroblast cells are responsible for the synthesis of collagen and ECM bio-macromolecules as well as the secretion of adherent proteins such as fibronectin. ${ }^{35}$ Therefore, the cell compatibility of the membrane 
keeps the normal rate of ECM synthesis, which is necessary for skin regeneration at the wounded site. The attachment of fibroblast cells revealed the compatibility of the electrospun membranes, confirming the results of the cell viability test. Cells exhibited normal morphology of fibroblasts on PEO and PEO/ZnO membranes (Fig. 5).

Skin scaffolds and wound dressings must have appropriate mechanical properties to support the healing process as well as the structures found in skin layers such as vessels and nerves. ${ }^{8,36}$ Herein, the mechanical properties of cross-linked and non-cross-linked electrospun scaffolds were evaluated and are presented in Fig. 7. At first glance, it is clear that cross-linked scaffolds exhibit higher mechanical parameters. As expected, the crosslinking of the membranes significantly improved their mechanical properties, which are comparable to those of native skin. The presence of $\mathrm{ZnO}-\mathrm{NPs}$ increased the Young modulus. Using wound dressings or scaffolds with great differences in mechanical properties leads to side effects caused by the stress-shielding mechanism during tissue regeneration. ${ }^{37}$ The excellent mechanical properties of the produced membranes could be attributed to the presence of a synthetic polymer (PEO) and the appropriate crosslinking protocol. ${ }^{38}$ The literature shows that metal nanoparticles enhance the mechanical characteristics of polymer nanofibers, ${ }^{39,40}$ but this was not significant in the current study due to the low concentration of $\mathrm{ZnO}-\mathrm{NPs}$.

The porosity of scaffolds is crucial to accommodate cells and facilitate their migration as well as the exchange of gas and nutrients. ${ }^{15}$ Incorporating $\mathrm{ZnO}$-NPs increased the porosity of the membrane, which can be explained by a lower diameter of $\mathrm{PEO} / \mathrm{ZnO}-\mathrm{NP}$ fibers and wider spaces between them. Other investigations have previously revealed that scaffolds with more than $90 \%$ porosity could provide the best opportunity for cell migration, ECM production, and gas and nutrient exchange for skin regeneration. ${ }^{41,42}$ In the current research, $\mathrm{PEO} / \mathrm{ZnO}-\mathrm{NP}$ membranes displayed porosity close to 90\% (Fig. 8), which demonstrates the suitability of the membrane for use in skin tissue engineering applications.

The physicochemical properties of the scaffold surface affect cell adhesion, proliferation and differentiation. ${ }^{43}$ Wettability is one of the most significant features of the surface of the material. ${ }^{44}$ Measuring water contact angle determines the surface wettability. ${ }^{45}$ According to other studies, moderate hydrophilic surfaces with a water contact angle between $30^{\circ}$ and $70^{\circ}$ have been shown to encourage cells to adhere and expand. Surface hydrophobicity and high hydrophilicity exhibit lower cell adhesion. ${ }^{46,47}$ In the current study, the electrospun PEO and $\mathrm{PEO} / \mathrm{ZnO}-\mathrm{NP}$ membranes showed water contact angle values similar to those of moderate hydrophilic substrates (Fig. 9). Such hydrophilicity could be attributed to the presence of functional groups such as hydroxyl groups. The presence of $\mathrm{ZnO}-\mathrm{NPs}$ in the structure de- creased the water contact angle (increased hydrophilicity) due to the presence of hydroxyl groups on its surface. ${ }^{48}$ In addition to cell adhesion, hydrophilic biomaterials can also provide the required moisture during the wound healing process. ${ }^{49}$

Body fluids contain large amounts of protein. Skin scaffolds and wound dressings are exposed to body fluids when they are placed at the wounded site, and protein adsorption begins immediately. The biological compatibility and cell adhesion of the material are directly affected by protein adsorption. Cells attach to the adsorbed proteins through their integral receptors, which anchor specific amino acids in the structure of adhesive proteins such as fibronectin. ${ }^{8}$ Albumin, the most abundant serum protein, is accumulated at the injured site during the primary phase of the wound healing process. The absorbed albumin is then replaced by cell adhesive proteins. ${ }^{50}$

The current results revealed that albumin absorption increased with time (Fig. 10). As expected, no statistically significant changes were observed between $\mathrm{PEO}$ and $\mathrm{PEO} /$ $\mathrm{ZnO}-\mathrm{NP}$ membranes due to their hydrophilic and porous surfaces. In addition to the moderate hydrophilicity (water contact angle measurement), the potential of these membranes for protein adsorption provides a qualified substrate for cell attachment, as shown in Fig. 5.

\section{Conclusions}

In the current investigation, the electrospinning technique was employed to fabricate scaffolds composed of PEO and ZnO-NPs. These membranes were supposed to mimic the native skin ECM in order to improve the wound healing process. To achieve the optimal concentration of incorporated $\mathrm{ZnO}-\mathrm{NPs}$, different concentrations of these nanoparticles were incorporated into PEO nanofibers and evaluated with disc diffusion and cell viability tests. The electrospun PEO containing 2\% of $\mathrm{ZnO}$-NPs exhibited antibacterial activity against E. coli and $S$. aureus without any toxicity to human fibroblast cells. Based on the results, the PEO membrane containing $2 \%$ of $\mathrm{ZnO}$-NPs was selected as the most biocompatible scaffold for further studies.

Evaluation of the physicochemical properties of the PEO/ZnO-NPs also confirmed the suitability of this highly porous ( $86.78 \pm 7.42 \%$ porosity) membrane for use as a skin scaffold. The high porosity of the membrane facilitates cell migration, nutrients and gas exchange, and provides adequate space for new ECM formation. The PEO/ZnO-NP scaffold showed a water contact angle value of $35.41 \pm 3.44^{\circ}$. The moderate hydrophilicity of the membrane could improve cell adhesion. Young's modulus of the cross-linked membrane $(28.15 \pm 4.49 \mathrm{MPa})$ indicates the appropriate mechanical support that can protect the wound during tissue remodeling and regeneration. 
In conclusion, the PEO electrospun nanofibrous membrane containing $2 \%$ of $\mathrm{ZnO}-\mathrm{NPs}$ showed suitable biological, physicochemical and mechanical properties as a skin scaffold. For further studies, the incorporation of alternative bioactive agents and molecules, such as vitamins, growth factors and ECM components, could improve the biological properties and enhance the performance of these electrospun membranes in skin tissue engineering.

\section{ORCID iDs}

Hamed Nosrati (1) https://orcid.org/0000-0002-6952-1109 Mohammad Khodaei (1) https://orcid.org/0000-0002-0598-8543 Mehdi Banitalebi-Dehkordi (1) https://orcid.org/0000-0002-4109-1493 Morteza Alizadeh (10) https://orcid.org/0000-0003-4214-6502 Shiva Asadpour (1) https://orcid.org/0000-0001-5574-7142 Esmaeel Sharifi (1) https://orcid.org/0000-0003-3400-3106 Jafar Ai (1) https://orcid.org/0000-0001-8417-5913 Mostafa Soleimannejad (1) https://orcid.org/0000-0002-9097-4356

\section{References}

1. Ehterami A, Salehi M, Farzamfar S, et al. Chitosan/alginate hydrogels containing alpha-tocopherol for wound healing in rat model. J Drug Deliv Sci Technol. 2019;51:204-213.

2. Dash BC, Setia O, Gorecka J, et al. A dense fibrillar collagen scaffold differentially modulates secretory function of iPSC-derived vascular smooth muscle cells to promote wound healing. Cells. 2020;9(4):966.

3. MacEwan MR, MacEwan S, Kovacs TR, Batts J. What makes the optimal wound healing material? A review of current science and introduction of a synthetic nanofabricated wound care scaffold. Cureus. 2017;9(10):e1736.

4. Keirouz A, Chung M, Kwon J, Fortunato G, Radacsi N. 2D and 3D electrospinning technologies for the fabrication of nanofibrous scaffolds for skin tissue engineering: A review. Wiley Interdiscip Rev Nanomed Nanobiotechnol. 2020;12(4):e1626.

5. Amiri N, Rozbeh Z, Afrough T, Sajadi Tabassi SA, Moradi A, Movaffagh J. Optimization of chitosan-gelatin nanofibers production: Investigating the effect of solution properties and working parameters on fibers diameter. BioNanoScience. 2018;8(3):778-789.

6. Vasita R, Katti DS. Nanofibers and their applications in tissue engineering. Int J Nanomedicine. 2006;1(1):15-30.

7. Okutan N, Terzi P, Altay F. Affecting parameters on electrospinning process and characterization of electrospun gelatin nanofibers. Food Hydrocolloids. 2014;39:19-26.

8. Miguel S, Ribeiro M, Coutinho P, Correia I. Electrospun polycaprolactone/aloe vera chitosan nanofibrous asymmetric membranes aimed for wound healing applications. Polymers (Basel). 2017;9(5):183.

9. Miguel SP, Moreira AF, Correia IJ. Chitosan based-asymmetric membranes for wound healing: A review. Int J Biol Macromol. 2019;127: 460-475.

10. Duan B, Dong C, Yuan X, Yao K. Electrospinning of chitosan solutions in acetic acid with poly(ethylene oxide). J Biomater Sci Polym Ed. 2004;15(6):797-811.

11. Augustine R, Malik HN, Singhal DK, et al. Electrospun polycaprolactone/ $\mathrm{ZnO}$ nanocomposite membranes as biomaterials with antibacterial and cell adhesion properties. J Polym Res. 2014;21(3):347.

12. Ahmed R, Tariq M, Ali I, et al. Novel electrospun chitosan/polyvinyl alcohol/zinc oxide nanofibrous mats with antibacterial and antioxidant properties for diabetic wound healing. Int J Biol Macromol. 2018;120(Pt A):385-393.

13. Hwang J-J, Ma T-W. Preparation, morphology, and antibacterial properties of polyacrylonitrile/montmorillonite/silver nanocomposites. Mater Chem Phys. 2012;136(2-3):613-623.

14. Sharma M, Yadav S, Ganesh N, Srivastava MM, Srivastava S. Biofabrication and characterization of flavonoid-loaded Ag, Au, Au-Ag bimetallic nanoparticles using seed extract of the plant Madhuca longifolia for the enhancement in wound healing bio-efficacy. Prog Biomater. 2019;8(1):51-63.
15. Zafari M, Mansouri Boroujeni M, Omidghaemi S, et al. Physical and biological properties of blend-electrospun polycaprolactone/chitosan-based wound dressings loaded with N-decyl-N, N-dimeth$\mathrm{yl}$-1-decanaminium chloride: $\mathrm{An}$ in vitro and in vivo study. $J$ Biomed Mater Res B Appl Biomater. 2020;108(8):3084-3098.

16. Antunes BP, Moreira AF, Gaspar V, Correia I. Chitosan/arginine-chitosan polymer blends for assembly of nanofibrous membranes for wound regeneration. Carbohydr Polym. 2015;130:104-112.

17. Liverani L, Lacina J, Roether JA, et al. Incorporation of bioactive glass nanoparticles in electrospun PCL/chitosan fibers by using benign solvents. Bioact Mater. 2018;3(1):55-63.

18. Samzadeh-Kermani A, Miri S. Synthesis, characterization and bactericidal property of chitosan-graft-polyaniline/montmorillonite/ ZnO nanocomposite. Korean J Chem Eng. 2015;32(6):1137-1141.

19. Anžlovar A, Orel ZC, Kogej K, Žigon M. Polyol-mediated synthesis of zinc oxide nanorods and nanocomposites with poly(methyl methacrylate). J Nanomater. 2012;2012:31.

20. Kooti M, Naghdi Sedeh A. Microwave-assisted combustion synthesis of ZnO nanoparticles. J Chem. 2012;2013:562028.

21. Fradique R, Correia TR, Miguel S, et al. Production of new 3D scaffolds for bone tissue regeneration by rapid prototyping. J Mater Sci Mater Med. 2016;27(4):69.

22. Lin X, Li Y, Luo W, et al. Leucine-activated nanohybrid biofilm for skin regeneration via improving cell affinity and neovascularization capacity. J Mater Chem B. 2020;8(35):7966-7976.

23. Chang W, Ma G, Yang D, Su D, Song G, Nie J. Electrospun ultrafine composite fibers from organic-soluble chitosan and poly(ethylene oxide). J Appl Polym Sci. 2010;117(4):2113-2120.

24. Cha JH, Didwal PN, Kim JM, Chang DR, Park C-J. Poly(ethylene oxide)-based composite solid polymer electrolyte containing Li7La3Zr2O12 and poly(ethylene glycol) dimethyl ether. J Membrane Sci. 2020;595:117538.

25. Son WK, Youk JH, Lee TS, Park WH. The effects of solution properties and polyelectrolyte on electrospinning of ultrafine poly(ethylene oxide) fibers. Polymer. 2004;45(9):2959-2966.

26. Bray R. Antibacterial wound dressing. Google Patents; 2014.

27. Kazımoğlu H, Uysal E, Dokur M, Günerkan RH. Evaluation of the relationship between neutrophil lymphocyte ratio and the most common bacterial urinary tract infections after transplantation. Bratisl Lek Listy. 2019;120(2):161-165.

28. Bui VKH, Park D, Lee Y-C. Chitosan combined with $\mathrm{ZnO}, \mathrm{TiO}_{2}$ and $\mathrm{Ag}$ nanoparticles for antimicrobial wound healing applications: A mini review of the research trends. Polymers (Basel). 2017;9(1):21.

29. Zhang X, Ren S, He X, et al. Preparation and characterization of cellulose nanofiber/zinc oxide composite films. J Biobased Mater Bioenergy. 2020;14(2):203-208.

30. Xia T, Kovochich M, Liong $M$, et al. Comparison of the mechanism of toxicity of zinc oxide and cerium oxide nanoparticles based on dissolution and oxidative stress properties. ACS Nano. 2008;2(10):2121-2134.

31. Lin W, Xu Y, Huang C-C, et al. Toxicity of nano-and micro-sized ZnO particles in human lung epithelial cells. J Nanoparticle Res. 2009; 11(1):25-39.

32. Bondarenko O, Juganson $K$, Ivask $A$, Kasemets $K$, Mortimer $M$, Kahru A. Toxicity of Ag, $\mathrm{CuO}$ and $\mathrm{ZnO}$ nanoparticles to selected environmentally relevant test organisms and mammalian cells in vitro: A critical review. Arch Toxicol. 2013;87(7):1181-1200.

33. Ghalei S, Nourmohammadi J, Solouk A, Mirzadeh H. Enhanced cellular response elicited by addition of amniotic fluid to alginate hydrogel-electrospun silk fibroin fibers for potential wound dressing application. Colloids Surf B Biointerfaces. 2018;172:82-89.

34. Dill V, Mörgelin M. Biological dermal templates with native collagen scaffolds provide guiding ridges for invading cells and may promote structured dermal wound healing. Int Wound J. 2020;17(3):618-630.

35. Maione-Silva L, de Castro EG, Nascimento TL, et al. Ascorbic acid encapsulated into negatively charged liposomes exhibits increased skin permeation, retention and enhances collagen synthesis by fibroblasts. Sci Rep. 2019;9(1):522.

36. Niu X, Wei Y, Liu Q, et al. Silver-loaded microspheres reinforced chitosan scaffolds for skin tissue engineering. Eur Polym J. 2020;134:109861.

37. Elsner JJ, Zilberman M. Novel antibiotic-eluting wound dressings: An in vitro study and engineering aspects in the dressing's design. J Tissue Viability. 2010;19(2):54-66. 
38. Bianco A, Calderone M, Cacciotti I. Electrospun PHBV/PEO co-solution blends: Microstructure, thermal and mechanical properties. Mater Sci Eng C Mater Biol Appl. 2013;33(3):1067-1077.

39. Dong H, Fey E, Gandelman A, Jones WE. Synthesis and assembly of metal nanoparticles on electrospun poly(4-vinylpyridine) fibers and poly(4-vinylpyridine) composite fibers. Chem Mater. 2006;18(8): 2008-2011.

40. Radwan-Pragłowska J, Janus L, Piatkowski M, Bogdal D, Matýsek D. Hybrid bilayer PLA/chitosan nanofibrous scaffolds doped with ZnO, $\mathrm{Fe} 3 \mathrm{O} 4$, and $\mathrm{Au}$ nanoparticles with bioactive properties for skin tissue engineering. Polymers (Basel). 2020;12(1):159.

41. Doulabi AH, Mirzadeh $\mathrm{H}$, Imani M, Bagheri-Khoulenjani S. Chitosan/polyethylene glycol fumarate blend films for wound dressing application: In vitro biocompatibility and biodegradability assays. Prog Biomater. 2018;7(2):143-150.

42. Ababzadeh S, Farzin A, Goodarzi A, et al. High porous electrospun poly( $\varepsilon$-caprolactone)/gelatin/MgO scaffolds preseeded with endometrial stem cells promote tissue regeneration in full-thickness skin wounds: An in vivo study. J Biomed Mater Res B Appl Biomater. 2020; 108(1):2961-2970.

43. Tserepi A, Gogolides E, Bourkoula A, et al. Plasma nanotextured polymeric surfaces for controlling cell attachment and proliferation: A short review. Plasma Chem Plasma Processing. 2015;36.
44. Rahimipour S, Salahinejad E, Sharifi E, Nosrati H, Tayebi L. Structure, wettability, corrosion and biocompatibility of nitinol treated by alkaline hydrothermal and hydrophobic functionalization for cardiovascular applications. Appl Surface Sci. 2020;506:144657.

45. Talebi A, Labbaf S, Karimzadeh F. Polycaprolactone-chitosan-polypyrrole conductive biocomposite nanofibrous scaffold for biomedical applications. Polym Composites. 2020;41(2):645-652.

46. Kumbar SG, Nukavarapu SP, James R, Nair LS, Laurencin CT. Electrospun poly(lactic acid-co-glycolic acid) scaffolds for skin tissue engineering. Biomaterials. 2008;29(30):4100-4107.

47. Miguel SP, Ribeiro MP, Brancal H, Coutinho P, Correia IJ. Thermoresponsive chitosan-agarose hydrogel for skin regeneration. Carbohydr Polym. 2014;111:366-373.

48. Ennaceri $\mathrm{H}$, Wang $\mathrm{L}$, Erfurt $\mathrm{D}$, et al. Water-resistant surfaces using zinc oxide structured nanorod arrays with switchable wetting property. Surf Coat Technol. 2016;299:169-176.

49. Jones V, Grey JE, Harding KG. ABC of wound healing: Wound dressings. BMJ. 2006;332(7544):777-780.

50. Arima $Y$, Iwata $H$. Effect of wettability and surface functional groups on protein adsorption and cell adhesion using well-defined mixed self-assembled monolayers. Biomaterials. 2007;28(20):3074-3082. 